\title{
Comunicación

\section{Mexicanos en Los Ángeles: audiencia transnacional y noticias de televisión}

\author{
GABRIEL ALBERTO MORENO ESPARZA ${ }^{1}$
}

Este artículo discute la recepción de noticias televisivas de los mexicanos en Estados Unidos y propone el término "audiencia transnacional" como alternativa al nacionalismo metodológico que persiste en el estudio del consumo mediático de los inmigrantes. Esta entrega es un esfuerzo por explorar el papel de los medios en experiencias contemporáneas de globalización.

PALABRAS CLAVE: transnacionalismo, análisis de la recepción, audiencias transnacionales, migración, globalización.
This article focuses on the television news reception of Mexicans in the United States. It draws on the notion of "transnational audiences" as an alternative to the methodological nationalism that frames the research on the media use of immigrant audiences. This intervention is an effort to explore the role of communication media in contemporary experiences of globalization.

KEY WORDS: transnationalism, reception analysis, transnational audiences, migration, globalization.

1 Universidad de Guadalajara, México.

Correo electrónico: gabrielmoren@gmail.com

Este artículo fue realizado en el marco del programa de Apoyos Complementarios para la Consolidación Institucional de Grupos de Investigación del CONACyT. 
La presente intervención adapta el discurso del "transnacionalismo" a la recepción de noticias por televisión de personas de origen mexicano en Estados Unidos. Con este propósito se propone el término "audiencia transnacional", en referencia a las colectividades de usuarios de los medios de comunicación que llevan a cabo partes de sus vidas en las sociedades de origen y destino de grandes flujos migratorios. El concepto reconoce que los inmigrantes actúan en al menos dos espacios nacionales y emplea el análisis de recepción para visualizar partes de sus experiencias físicas y mediadas. Este espacio se presta para un sinfín de transacciones que se materializan de manera cotidiana, ya sea en miles de cruces fronterizos o en el envío de remesas, y sirve para pensar en la "audiencia transnacional" como un concepto alternativo al de los públicos "minoritarios" o "étnicos". Estos adjetivos han sido la base de un paradigma empleado principalmente por la academia estadounidense para estudiar el uso y consumo mediático de públicos migrantes. Desafortunadamente, éstos descansan en formas de "nacionalismo metodológico" (Wimmer \& Schiller, 2002) que a priori marginan a sus sujetos de estudio, al utilizar categorías de exclusión (etnicidad y estatus de minoría) como filtros para explicar el consumo de televisión, radio y medios impresos de los públicos nonatos en territorio nacional. Hoy se hace indispensable actualizar los paradigmas para explorar el consumo mediático de la gente que cambia su país de residencia, debido a que los procesos de asimilación, aculturación o adaptación en los que se encajona al público migrante son incompatibles con las experiencias locales y globales que tiene en su vida cotidiana.

Con el fin de defender este argumento el presente artículo se dividirá en cinco secciones. La primera es una síntesis teórica del transnacionalismo. La segunda da un vistazo a la literatura del análisis de la recepción y plantea su adaptación a contextos transnacionales. La tercera mezcla unas notas metodológicas sobre el caso de estudio en el que se basa este texto y da un vistazo a las noticias de televisión en español. En las secciones cuatro y cinco se trabaja con información obtenida en el consulado mexicano de Los Ángeles, a fin de visualizar algunos ámbitos de actividad y temas de atención que pueden ser comunes en la vida de los inmigrantes. Tanto los asuntos que tenían que tratar en la representación consular como las noticias televisivas de su interés -se 
espera concluir- sustentan el perfil de los informantes como actores en un espacio transnacional.

\section{TRANSNACIONALISMO EN CONTEXTO}

La creciente importancia de Internet y de plataformas inalámbricas para el uso y consumo de información digital genera la sensación de que hablar de la audiencia es un ejercicio fútil enterrado en el pasado. ${ }^{2}$ No obstante, la mayoría de las personas en sociedades contemporáneas se involucra de manera cotidiana como "lectora" de "textos", en una relación que permanece al centro del debate de los estudios cualitativos de la recepción (Bird, 2009). Y aunque pareciera que todo ha sido escrito en relación con la audiencia quedan fenómenos por conceptualizar, entre ellos la cuestión de "la audiencia transnacional". El uso de este concepto propone una fusión de los estudios del transnacionalismo con el análisis cualitativo de la recepción. A manera de definición, la audiencia transnacional se compone de comunidades -valga la redundancia - transnacionales formadas por inmigrantes y los círculos de interacción que éstos mantienen en sus países de origen y destino. Esta conceptualización permite explorar lo que el uso y consumo mediático puede revelar sobre experiencias contemporáneas migratorias en un contexto globalizado (Moreno, 2009). Lo que se propone aquí es que, antes de pensar en el inmigrante como público consumidor de los medios de comunicación, hay que verlo como un actor social con prácticas culturales, económicas y políticas en sus países de origen y destino. Partiendo de la Teoría de Estructuración de Anthony Giddens, puede afirmarse que las personas que emigran "tienen la capacidad de entender lo que hacen en el momento que lo están haciendo" y sus capacidades reflexivas "están involucradas de manera continua con el flujo de conductas cotidianas en el contexto de su actividad social" (1984, pp.

2 Esto debido a la noción de que la audiencia es ahora autora y co-creadora potencial de los contenidos que circulan principalmente en Internet, pero que convergen vertical y horizontalmente con los medios masivos de comunicación (Jenkins, 2006; Leadbeater, 2008). 
XXII-XXIII). ${ }^{3}$ El transnacionalismo es afín con esta idea porque, como se ha escrito, los "inmigrantes construyen campos sociales que atraviesan fronteras geográficas, culturales y políticas" (Basch, Schiller \& Szanton, 1994, p. 7).

Aunque por cuestiones de espacio es poco productivo intentar una revisión detallada de la literatura sobre el transnacionalismo, hay que considerar algunos de sus elementos clave. ${ }^{4}$ Aquello que es "transnacional" se emplea actualmente en un sinfín de contextos, sobre todo para describir las operaciones de una clase capitalista transnacional (Sklair, 1998). Empero, el término es idóneo para describir actividades como la formación de asociaciones paisanas (Smith, 1998), de redes religiosas (Levitt, 2001), políticas (Smith \& Bakker, 2005) y de comercio en zonas fronterizas (Álvarez, 1994). Éstas generan un sentido de pertenencia a un espacio transnacional (Long \& Villarreal, 1998) y constituyen un movimiento de "globalización por abajo" (Faist, 1999; Portes, 1997; Smith \& Guarnizo, 1998). En este sentido los migrantes actúan en los márgenes de estructuras laborales, y sus prácticas son una respuesta a las cambiantes condiciones que resultan del despliegue global del capital (Portes, 1997, p. 3-4; Rouse, 1996, p. 254).

La región cubierta por el Tratado de Libre Comercio de América del Norte (TLCAN) ha estimulado el trabajo en el área. A inicios de la década pasada el antropólogo Roger Rouse (1996/1991) documentó

3 La totalidad de las citas presentadas corresponde a traducciones de los textos en inglés realizadas por el autor. Este artículo usa información obtenida durante el trabajo de campo realizado en Los Ángeles entre el 26 de junio y el 28 de septiembre de 2006. Las actividades de investigación fueron parte de un programa doctoral completado en junio de 2009 en la Universidad de Westminster, Londres, Inglaterra. Los datos que se utilizan aquí quedaron excluidos de la tesis doctoral por cuestiones de espacio.

4 Un sinfín de autores y publicaciones académicas tales como Diaspora, Public Culture y Global Networks han documentado la magnitud de la tendencia. Aunque los vínculos entre fuentes emisoras y receptoras de grandes flujos migratorios han existido incluso desde antes de la formación del estado-nación, su práctica se ha intensificado en magnitud y frecuencia en décadas recientes (Portes \& Rumbaut, 2006, p. 131; Vertovec, 1999). 
la forma en la que mexicanos del estado de Michoacán que residen en Redwood, California, "encuentran que sus parientes y amigos más importantes se encuentran a su lado pero también a cientos o miles de millas" (p. 253). La noción del transnacionalismo hace evidente que emigrar no puede entenderse como el simple cambio de un orden social a otro distinto (Rouse, 1996/1991, p. 249). E1 establecimiento relativamente reciente de "circuitos" de actividad transfronteriza, en este sentido, hace obsoletas las metáforas que se han aplicado al tratamiento académico de la migración, donde a menudo se habla de "desprendimiento" (Handlin, 1973), "exilio" (Ahmed, 2003) y “aislamiento" (Ahmed, 1999). En la actualidad, los inmigrantes raramente están aislados, pues tienen la capacidad de viajar al lugar de origen o de contactar a sus familiares y amigos a voluntad. Además, en sus lugares de destino crean espacios donde recrean relaciones y prácticas sociales en las que se reconstituyen identidad y sentido de pertenencia a "comunidades imaginarias" (Anderson, 1991; Appadurai, 1996). 5 Puede añadirse que los espacios transnacionales son el resultado de una progresiva interpenetración

5 Estas comunidades imaginarias no son, sin embargo, estáticas. Mientras que el transnacionalismo permite observar la "desterritorialización" de la cultura (García-Canclini, 1995) y la producción de lo "translocal" (Appadurai, 1996, p. 192; Mandaville, 2002), también hace visible que la migración contemporánea es parte de un orden "post-colonial” (Bhabha, 1994, p. 173) o "post-nacional” (Appadurai, 1996, 2003) en el que las poblaciones desplazadas por el proceso de globalización definen sus identidades en términos pragmáticos o flexibles (Ong, 1999), y no sólo en función de orígenes étnicos o nacionales (Castells, 2004). Lo anterior significa que el transnacionalismo no privilegia el sentido de pertenencia a una comunidad imaginaria con sede en el país de nacimiento. En este orden de ideas, el concepto Diáspora contribuye a tomar en cuenta la formación de nuevas asociaciones políticas, económicas y culturales que las comunidades transnacionales establecen en sus lugares de destino. Este entendimiento llama así nuestra atención no sólo a un sentimiento de nostalgia o al deseo de volver al viejo terruño, sino a la voluntad de crear nuevos hogares en los lugares de destino (Brah, 1996, p. 179; Clifford, 1994, p. 302). 
económica, política y cultural dada a través del tiempo, y que en el caso de México y Estados Unidos son amplificados por las rutas terrestres, ferroviarias y aéreas que actúan como un caldo de cultivo para la actividad transnacional (Roberts, Frank \& Lozano, 1999, p. 244). Vale además recordar que la globalización de los medios masivos de comunicación se traduce en el hecho de que empresas de comunicación del "sur global" como Televisa (México), Rede Globo (Brasil) o Al Jazeera (Qatar), pueden difundir sus contenidos más allá del territorio nacional en el que están establecidas. Los flujo y contraflujos mediáticos (Thussu, 2007) han estimulado el estudio de la comunicación transnacional, que por lo general documenta la producción y difusión mediática, más que su recepción.

El transnacionalismo es una herramienta de análisis que permite reorientar el foco de atención en relación al uso y consumo de los medios de comunicación de los inmigrantes. A través de los años se ha promovido el principio rara vez cuestionado de que éstos utilizan los medios de comunicación para "asimilarse" a la cultura del país receptor, o para "retener" su cultura de origen. ${ }^{6}$ Teorías basadas en la asimilación, la aculturación y más recientemente la incorporación de migrantes, "se han dedicado a vigilar la transformación de los inmigrantes en ciudadanos, y a evaluar de qué manera pueden afectar la estabilidad y dirección del sistema político estadounidense" (Portes, Escobar, \& Arana 2008, p. 2). Esta noción se ha asentado tanto en sectores letrados como en una multitud de escaparates populares, incluidos los medios de comunicación, donde a menudo se refuerza la idea de que los inmigrantes tienen que asimilarse a la cultura anglosajona. En una reciente intervención pública, el gobernador de California Arnold Schwarzenegger, por ejemplo, recomendó a los mexicanos en Estados Unidos dejar de ver televisión en español si es que desean convertirse en "americanos" (Foxnews.com, 2007).7

6 Un amplio y bien informado resumen de esta literatura ha sido escrito por Subervi-Vélez (1986).

7 Sin mencionar la palabra "asimilación", la recomendación de Schwarzenegger hizo eco con el pensamiento de ideólogos conservadores que han argumentado que los bajos niveles de escolarización y de desempeño eco- 
Aunque en la actualidad la academia se ha alejado de los términos "asimilación” y "aculturación", persisten perspectivas de audiencias “étnicas” o "minoritarias" (Johnson, 2000; Ríos, Gaines \& Stanley, 1999) que utilizan los medios para mantener su identidad cultural (Mayer, 2003; Valdivia, 2003), incluso de manera "situacional" (Subervi \& Ríos, 2005). Esta noción propone que los inmigrantes y sus hijos controlan aspectos de sus identidades culturales, de forma que bailar salsa o ver televisión en español es una actividad que llevarían a cabo sólo ante miembros del propio grupo étnico. Por el contrario, los mismos individuos tenderían a esconder sus comportamientos minoritarios cuando estén en un contexto social en el que prevalezcan miembros de la cultura dominante.

La idea de que los inmigrantes consagran su consumo mediático al objetivo de adaptarse a la sociedad anfitriona o al de retener la cultura de origen, equivale a decir que los medios de comunicación tienen el poder de modificar o consolidar la identidad cultural de los individuos. Las categorías de análisis de este paradigma lo hacen afín al modelo de transmisión hipodérmica, de acuerdo al cual los medios de comunicación pueden provocar ciertos comportamientos y cambios de actitud (Negus \& Román-Velázquez, 2000), particularmente entre los sectores más vulnerables y desfavorecidos de la sociedad (Morley, 2006, p. 103). La postura de este artículo es que las perspectivas de asimilación o pluralismo cultural presente en el estudio de los públicos étnicos o minoritarios están basadas en formas de "nacionalismo metodológico" que marginan a sus sujetos de estudio. En este caso, el nacionalismo metodológico ha significado que el público migrante ha sido entendido

nómico de la población de origen mexicano en Estados Unidos deriva de su incapacidad de asimilarse. En 1923, por ejemplo, Emory S. Bogardus sugirió que "la mezcla de razas" (p. 264), el analfabetismo y la pobreza extrema de los inmigrantes mexicanos obstaculizaban su capacidad de aprender inglés "o de conocer las mejores fases de la vida en Estados Unidos" (p. 266). Ocho décadas después, autores neo-conservadores insisten en difundir argumentos similares. Samuel Huntington, por ejemplo, escribió que su insistencia en hablar español convierte a los mexicanos en una amenaza a la integridad cultural y lingüística de Estados Unidos (2004, p. 38). 
a priori como una anomalía, como "no pertenecientes" al territorio nacional, cuyo uso y consumo de los medios de comunicación debe ser investigado bajo criterios diferentes a los empleados para la "audiencia nacional", aquella que "sí pertenece".

\section{ANÁLISIS DE RECEPCIÓN}

PARA LA AUDIENCIA TRANSNACIONAL

Partiendo de las aseveraciones hechas en la última sección, sabemos que la noción de la audiencia transnacional tiene entre sus objetivos reconocer al migrante como actor social, desechando cualquier vínculo con el modelo de transmisión hipodérmica. Con este fin hay que adoptar categorías de análisis propuestas por la escuela de Estudios Culturales y del análisis de la recepción. Estas dos ramas son afines en su acercamiento a las audiencias, al considerar que su objeto de estudio radica fuera de los medios (Jensen \& Rosengren, 1990, p. 213). Dicho lo anterior se asume que la audiencia transnacional se compone por "lectores" de contenidos televisivos, radiofónicos, impresos, y más recientemente digitales, que decodifican estos textos a través de prácticas sociales (Hall, 2001; Moores, 1993, pp. 5-6). Estas prácticas y los actos de representación simbólica que las constituyen son un reflejo de la realidad social. Se da por hecho pues que la audiencia es activa y selectiva (Alasuutari,1999; Fiske, 1989, 1994; Jenkins, 1992), capaz de negociar y resistir las "lecturas preferidas" que residen, de manera codificada, en todo texto mediático (Hall, 2001). Sirve agregar que las audiencias están compuestas por miembros de "comunidades interpretativas" (Lindlof, 1988) inmersas en contextos históricos específicos. Categorías de análisis sociológico como género y edad (Hobson, 1978; Lemish, Liebes \& Seidman, 2001), clase (Morley, 1980) y nacionalidad (Liebes \& Katz, 1990), entre otras, son de utilidad para evaluar las prácticas interpretativas de las audiencias. Es de vital importancia, además, considerar que las estructuras de poder presentes en los contextos "naturales" de recepción (Lindlof, 1987) se reflejarán en la misma interpretación de los textos (Moores, 1993, p. 5; Silverstone, 1994, p. 151).

Puesto que el uso y consumo mediático contiene claves para entender la realidad social, el análisis de recepción debe situarse además 
en el contexto cotidiano de las audiencias. En el caso de la recepción televisiva esto implica explorar la manera en que el consumo de programas por televisión se articula con las rutinas del espacio doméstico (Gauntlett \& Hill, 1999; Silverstone, 1994). Esta perspectiva ha permitido documentar una variedad de rituales que ocurren en el entorno del espacio televisual, tales como la limpieza del hogar (Bryce, 1987), disputas familiares (Gunter \& Svennevig, 1987) y el cuidado de los niños (Jensen-Leichter, Ahmed, Barrios, Bryce, Larcen \& Moe, 1985). También se sabe que la televisión es usada para fomentar la interacción o el aislamiento familiar (Lull, 1980, 1990, 1998), y que el drama de las telenovelas es útil como consuelo de quienes realizan las labores -no remuneradas- de la limpieza doméstica (Hobson, 1982). De aquí se ha desprendido también que la programación revela diferencias de género: las mujeres ven telenovelas (Brunsdon, 1981; Hobson, 1980), los hombres ven noticias (Morley, 1986) y tienen la última voz al decidir quién controla la programación y al ser los principales operadores de aparatos electrónicos, incluido, por supuesto, el control remoto (Lull, 1982; Morley, 1986; Yarto \& Lozano, 2004).

Al dar cuenta de las prácticas sociales cotidianas en el entorno doméstico el análisis de la recepción vislumbra, en consecuencia, el carácter de las audiencias como entidades privadas y públicas (Morley \& Silverstone, 1992, p. 32). El concepto "privatización móvil" (Williams, 2003, pp. 134-146) indica, en este sentido, que las interfaces impresas y electrónicas de los medios de comunicación proyectan a los usuarios al ámbito de la polis, involucrándolos en procesos de intercambio simbólico y material (Silverstone, 1991, p. 140-144). Así pues, "la economía moral del hogar promueve su incorporación con el mundo exterior" (p. 46), de tal manera que las audiencias participan desde su casa en eventos públicos significantes (Dayan \& Katz, 1992), y pueden experimentar lo distante a través de la pantalla misma (Thompson, 1995, p. 208). La implicación es que la audiencia no está sólo compuesta de televidentes, radioescuchas o lectores de periódicos, sino de agentes sociales con interacciones entre lo privado y lo público (Silverstone, 1991, p. 136). Esta perspectiva ha sido sistemáticamente empleada para analizar a la audiencia "que sí pertenece" al territorio nacional, pero apenas comienza a utilizarse en el caso de las comunidades transnacio- 
nales. Más acercamientos empíricos de esta naturaleza son necesarios, específicamente en el caso de los mexicanos en Estados Unidos, para conocer los roles que los medios de comunicación y otras tecnologías de información tienen en la creación de lo que ha sido denominado como "esferas públicas transnacionales" (Appadurai, 1996, p. 22; Cunningham, 2004; Morley, 2000, p. 3).

En un contexto globalizado es preciso replantearse la dimensión evocada por la intrínseca relación entre lo público y lo privado. Hasta hace unos años se pensaba en las audiencias como un constructo análogo a la "población", "la nación" o "el país" (Ang, 1991, p. 2). Baste como ejemplo la forma en que los jefes de Estado utilizan la televisión para dar informes de gobierno o para asumir el poder. El 20 de febrero de 2009 Barack Obama, un botón de muestra, inició su discurso inaugural dirigiéndose a my fellow citizens (algo así como "queridos compatriotas") (Obama, 2009). Aunque parezca obvio dirigirse a la audiencia como si ésta fuera la nación, hay que tomar nota de que conceptualizarla es una tarea cada vez más compleja. Esto es así sobre todo en países receptáculo de densos flujos migratorios donde los horizontes étnicos y culturales (Hannerz, 1996) se han transformado de manera dramática, a medida que los espacios urbanos se han convertido en centros de globalidad (Sassen, 2001). Por lo tanto, se hace necesario pensar en la audiencia transnacional como un fenómeno que modifica esencialmente nuestro entendimiento del binomio público-privado. ${ }^{8}$ Esto significa que para algunos, lo público y privado está contenido en el espacio nacional. En contraste, para los integrantes de comunidades transnacionales lo público y privado se puede confundir con lo local y lo global, debido a que la ubicación del hogar, del barrio o la colonia, la ciudad, la nación y el extranjero, se distribuye de manera ambivalente a lo largo del espacio transnacional. Estas consideraciones resultan más que simples abstracciones. A medida que el espacio nacional es penetrado por las conexiones transnacionales

8 La definición de lo "privado" y lo "público" siempre ha sido compleja (Arendt, 1998) pero en el contexto que nos ocupa lo privado remite al espacio individual donde se satisfacen las necesidades más básicas, y que permanecen ocultas en relación al "espacio de las apariencias" (Arendt, citada en Canovan, 1994, p. 180), donde la vida en sociedad tiene lugar. 
de la audiencia, el vínculo entre lo privado y lo público se muestra, por ejemplo, a través de la convergencia de sistemas nacionales y transnacionales de los medios de comunicación. Para millones de mexicanos en Los Ángeles, Houston o Nevada, esto se manifiesta en que pueden saltar de un noticiero local en inglés, a una comedia transmitida por Univisión, y a un noticiero por cable de Televisa. Es así que uno puede comenzar a imaginar una teoría de la "esfera pública" transnacional, un concepto que los teóricos saben que existe pero que permanece frágilmente articulado (Fraser, 2007). El análisis de la recepción puede ser útil en este sentido. Al ubicarse en el espacio doméstico del "hogar transnacional" emergen dinámicas que son penetradas por la realidad cotidiana de las sociedades receptoras, lo mismo que por la presencia de personas, objetos y símbolos que remiten al país de origen. Así, los visitantes, los retratos familiares, las llamadas telefónicas, los viajes y programas de televisión, conectan lo doméstico a una realidad transnacional.

\section{METODOLOGÍA Y NOTICIAS:}

ENFOQUE EN LA COTIDIANIDAD

Conviene ahora reflexionar sobre el caso de estudio tratado en esta entrega, el cual se desprende de un proyecto de investigación doctoral que en 2006 utilizó la elección presidencial en México como contexto clave para explorar el uso y consumo de las noticias de televisión de la diáspora mexicana en Estados Unidos. ${ }^{9}$ Frente al hecho de que esa contienda era la primera en la historia que abría el proceso electoral a ciudadanos mexicanos residentes en el extranjero, el objetivo era indagar

9 Este texto evitará distraerse con la cuestión de si la población de origen mexicano en Estados Unidos es cubierta por el concepto de "diáspora". Aunque expertos en el tema como Robin Cohen (1997) encuentran que una comunidad de inmigrantes debe estar dispersa en dos o más países para poder definirse propiamente como tal (1997, p. 22), nuestro entendimiento es que el concepto, como afirman una variedad de autores (González, 1999; Tölölyan, 1991, 1996), presenta incentivos de carácter discursivo que pueden fortalecer los argumentos de comunidades inmigrantes en lo relativo a sus relaciones con una variedad de actores ubicados en sus países de origen y destino. 
el potencial de la televisión y del género noticioso para activar procesos de participación política transfronterizos. Para julio de 2006 ya se sabía que menos de $2 \%$, de un total de 3 millones de mexicanos elegibles en Estados Unidos, se había registrado para participar en la elección (Suro \& Escobar, 2006). Más que pensar que la cobertura informativa de las campañas electorales y de la elección misma fomentarían el voto, el diseño de la investigación estaba orientado a capturar la generación de argumentos y opiniones, discusiones familiares, uso de tecnologías y otras actividades que indicaran alguna relación entre el uso y consumo de las noticias por televisión con un sentido de pertenencia a la nación mexicana. La hipótesis estaba basada en la idea de que los medios de comunicación reducen la importancia de las fronteras geográficas, al tiempo que fomentan prácticas de desterritorialización cultural (GarcíaCanclini, 1995) y de reproducción de identidades colectivas (Morley \& Robins, 1995) y comunidades imaginarias (Anderson, 1991).

Luego de analizar la información generada por una metodología predominantemente cualitativa, 10 emergieron señales que contradecían a la tesis original. Los informantes, por ejemplo, demostraron escepticismo y un escaso interés en la cobertura de la elección mexicana, en contraste con un seguimiento firme de informes sobre un debate legislativo encaminado a reformar la ley migratoria de Estados Unidos, sobre la guerra en Irak, el estado de la economía estadounidense, salud, educación, etc. Lejos de indicar que los medios de comunicación carecen de importancia para explicar relaciones de carácter extraterritorial entre los inmigrantes y sus países de origen, la presencia de contradicciones nos presenta la oportunidad de investigar lo que el análisis de la recepción puede contribuir para el estudio del transnacionalismo. Esta perspectiva hace visibles las múltiples interacciones y prácticas sociales del

10 Un total de 67 informantes participaron en las actividades de investigación, dando lugar a 25 entrevistas semi-estructuradas y 25 sesiones domésticas en las que individuos y familias vieron y discutieron sus programas favoritos de noticias. Los participantes también escribieron reportes cotidianos de las noticias que vieron durante varias semanas. El trabajo de campo fue ampliado luego de que se consiguió acceso al consulado de México en Los Ángeles, y que dio lugar al material empleado para este artículo. 
migrante y permite profundizar nuestro conocimiento de la forma en que los seres humanos que cambian de país de residencia experimentan el proceso de globalización. Después de todo, la globalización no es sólo algo "que está 'allá afuera', remoto y distante del individuo, sino también un fenómeno que está 'aquí', influyendo aspectos íntimos y personales de nuestra existencia" (Giddens, 1999, p. 12).

A fin de delimitar el volumen de información que aquí se presenta, este artículo utilizará únicamente las respuestas obtenidas en ocho entrevistas estructuradas a usuarios de servicios prestados por el consulado de México en Los Ángeles. La entrevista incluyó cinco preguntas concentradas en el asunto que los informantes tenían que tratar en la representación consular y en las últimas noticias por televisión que recordaban haber visto (Moreno, 2009, pp. 136-137). Las respuestas se presentarán a través de citas cortas en las que sólo se incluirá el nombre sin apellido de los entrevistados, de acuerdo a la práctica estándar de escritura académica. El texto se complementará con algunos datos producto de una encuesta aplicada a 106 mujeres y hombres en el mismo lugar. La información discutida sugiere que las noticias televisivas de interés para los informantes y los trámites que los ocupaban al momento de acudir al consulado reflejan su carácter como actores transnacionales. Mientras que estas actividades sugieren una fuerte orientación hacia el país de nacimiento, también se advierte la presencia de prácticas y reflexiones vinculadas con el país receptor, que refuerzan la noción del espacio transnacional como un fenómeno que trasciende el nacionalismo metodológico.

Antes de discutir nuestros hallazgos es importante hablar de las noticias televisivas como un género factual que revela las experiencias cotidianas de quienes las ven (Hill, 2007, p. 97). En términos generales, las noticias nos remiten a un tipo de "información regularmente actualizada y con representaciones de sucesos recientes y significativos para un área geográfica o una esfera de actividad" (Corner, 1995, p. 55). Independientemente de que las noticias sean un producto que resulta de las prácticas y rutinas de la profesión periodística (Schudson, 2000), éstas son reflejo de una realidad que cubre necesidades individuales y colectivas para el monitoreo del entorno (Jensen, 1998, p. 9). En pocas palabras la audiencia sabe que las noticias son de importancia, 
pues incorporan supuestos de lo que tiene relevancia (Schudson, 1995, p. 14). Valga además indicar que la recepción de noticias se manifiesta a través de "súper temas", los cuales permiten visualizar "los intereses dominantes de la audiencia" (Orozco, 1998, p. 127). En correspondencia, una de las preguntas que se hizo a quienes participaron en nuestro ejercicio indagó cuál había sido el último reporte que recordaban haber visto. Se propone que cada respuesta refleja aquello que los informantes consideran de importancia. Así, es razonable pensar en las noticias como una narrativa de lo cotidiano, "del trasfondo a través del cual la gente piensa" (Schudson, 1995, p. 16).

Son las noticias de Univisión y Telemundo las que informan la percepción cotidiana de los mexicanos en Estados Unidos. Estas televisoras cubren 99 y $93 \%$, respectivamente, de los 11.2 millones de hogares hispanos (Telemundo, 2008; Univision, 2007, p. 8). ${ }^{11}$ Mientras que los programas de entretenimiento producidos en México son ampliamente seguidos por la audiencia hispanohablante de Estados Unidos, puede aventurarse que en tiempos recientes - de manera paradójica que no puede analizarse con detalle en este artículo- los programas noticiosos, ya sea de Televisa o TV Azteca tienen poca relevancia para la audiencia transnacional.12 Esto no significa que los mexicanos no se interesan en las noticias de México, sino que los noticieros de este país no contienen el tipo ni la cantidad de información sobre sus lugares de residencia. Además, los inmigrantes mexicanos suelen desconfiar de los noticie-

11 La población de origen mexicano representa casi $10 \%$ de la población estadounidense y $65 \%$ de la gente de origen hispano en ese país (ACS, 20052007).

12 En la encuesta realizada en el consulado de Los Ángeles, por ejemplo, sólo 8 de 106 personas consultadas dijeron seguir las noticias de Televisa por Galavisión, mientras que 63 dijeron ver Univisión y el resto se dispersó en otros noticieros, predominantemente entre Telemundo y Canal 22 Los Ángeles. No se desea aquí, sin embargo, atribuir gran importancia a cualquier conteo que pueda asemejarse a la idea del rating, pues como se sabe, estos oscurecen la relación de la audiencia con los contenidos audiovisuales, y son sólo relevantes en tanto que un cálculo institucional que sirve a los objetivos comerciales de las televisoras (Ang, 1991, p. 7). 
ros mexicanos pues ven a Televisa particularmente (Sinclair, 1999, p. 103) como parte del régimen que fracasó en crear las oportunidades para que vivan en su país de nacimiento. Muchos de los presentadores y periodistas que laboran para estas firmas han sido en el pasado empleados de Televisa, pero se caracterizan por sus estilos críticos y no oficialistas, lo cual funciona como una declaración de independencia política (Rodríguez, 1999, p. 86). Con excepciones, los mexicanos han volcado su preferencia a los noticieros de Univisión y Telemundo, dos productos estadounidenses en español que manifiestan valores de producción de los noticieros en inglés (c. 4-5). La diferencia es que éstos se distinguen por promover los intereses de la gente de origen mexicano en particular y latinoamericano en general. Los mecanismos a través de los cuales se producen las noticias proyectan una visión de la audiencia como empobrecida, mestiza y poco escolarizada (p. 47). La forma en que la audiencia es vista por los productores de noticias queda manifiesta en los titulares de los noticieros. En estos prevalecen temáticas como migración y estatus residencial, acceso a casa-habitación, servicios de salud y educación, criminalidad, relaciones interétnicas, empleo, servicios comunitarios, así como cuestiones de gobernabilidad y derecho tributario que a menudo pueden ser confusas para personas recién llegadas o sin un manejo eficiente del inglés. En otras palabras, las noticias en español ponen al aire imágenes de aquello que afecta directamente a los mexicanos y otras comunidades latinas como la audiencia imaginada por los productores (1999, p. 1). Por otro lado, los telenoticieros en español proyectan a una audiencia en un marco de referencia dual que contempla a los hispanos en Estados Unidos y que provee abundante cobertura noticiosa de América Latina. Esta región es entendida como un vasto contenedor cultural de una "comunidad imaginaria" subcontinental (Sinclair, 2004) con la cual los televidentes -supuestamente- se identifican. Mientras que este análisis es interesante, fuera de esta dicotomía existen dimensiones por explorar. Este ejercicio requiere concentrarse en la producción de significado que las audiencias generan a partir de los textos televisivos. Esta perspectiva desde la recepción rara vez se ha utilizado para estudiar a los públicos migrantes $\mathrm{y}$, sin embargo, permite responder a preguntas como las que ocupan a este caso de estudio: ¿qué hacen las audiencias transnacionales con las 
noticias de televisión que ven?, ¿de qué forma sus reflexiones a partir de las noticias nos permiten entender algunas experiencias contemporáneas de migración?, ¿qué nos dice la recepción de noticias sobre la cotidianeidad en espacios transnacionales? La siguiente sección buscará utilizar información obtenida en el consulado de Los Ángeles para aportar algunas respuestas tentativas.

\section{ESPACIOS DE TRANSNACIONALIDAD}

Como la representación consular más grande de México en el mundo, el consulado de Los Ángeles atiende a unas 600 personas que diariamente acuden a solicitar servicios de registro civil, documentos de viaje e identificación (Consulado, 2009). Puede pensarse en el consulado como una proyección del espacio transnacional en el que los inmigrantes habitan. Documentos como la matrícula consular, por ejemplo, les permiten identificarse como ciudadanos mexicanos, ya sea que se encuentren en Nueva York o en la Ciudad de México (Nevaer, 2007). Este efecto de extraterritorialidad es un designio del gobierno mexicano para mantener una esfera de influencia en Estados Unidos (González, 1999, p. 545), pero esta política ha sido sólo una respuesta a las iniciativas de los migrantes mexicanos como precursores de las actividades transnacionales (Portes \& Rumbaut, 2006, p. 136). La idea es que el transnacionalismo se manifiesta en los campos de acción de las personas que componen sus espacios y que pueden visualizarse a través de los usos que dan a la documentación obtenida en el consulado. De las ocho entrevistas empleadas para esta contribución, por ejemplo, todos los informantes expresaron recurrir al consulado para tratar asuntos en México desde Estados Unidos. Estos incluyen enviar posesiones y vehículos, tramitar poderes notariales o inscribir a un familiar en el Instituto Mexicano del Seguro Social (IMSS). Lo anterior refleja una constante interacción en dos espacios nacionales, como lo sugiere un entrevistado:

Vine para sacar la matrícula (consular) de mi esposa y para informarme sobre los menajes para casas, para llevar a México unos aparatos y muebles. Así mato dos pájaros de un tiro, resuelvo cosas de aquí y de allá (Jesús, 48 años, Ciudad de México). 
Otro usuario dijo que había acudido al consulado para solicitar un poder notarial que su esposa utilizaría para vender una propiedad en la capital mexicana. Las acciones extraterritoriales son sin embargo parte de un proceso ambivalente cuya fluidez es interrumpida por obstáculos como la nacionalidad y el estatus migratorio de las personas. Como expuso una informante:

Vengo a sacar mi pasaporte ... pero tengo un problema porque mi esposo no puede viajar. Yo estoy legal pero él se vino sin papeles, así que creo que voy a viajar sola (Elba, 27 años, Ciudad Guzmán).

Las estructuras de gobierno que regulan la forma del espacio transnacional también aplican para aquellos que han resuelto del todo cuestiones de ciudadanía y residencia, como lo expresó un hombre que había radicado en Los Ángeles desde 1989, y quien ahora estaba considerando obtener la ciudadanía mexicana de su hija de 12 años.

Ella es gringuita, nació aquí, pero ahora estoy necesitando viajar más seguido a México y creo que es más fácil si ella se hace mexicana, con doble nacionalidad; ¿no? (Héctor, 49 años, Zacatecas).

Con más de 6 millones de mexicanos que residen en Estados Unidos sin autorización (Pew, 2006), sería difícil argumentar que todos tienen la movilidad política o económica generalmente atribuida a los actores transnacionales. No obstante, las actividades a distancia en que participan los inmigrantes son un aspecto significante de sus experiencias cotidianas, y centrales para entender el fenómeno de la transnacionalidad. El envío de remesas, las llamadas telefónicas, la interacción con personas que vienen y van, el consumo de programas de televisión, etc., proyectan al inmigrante en una esfera de actividad extraterritorial. Ésta se hizo tangible en la encuesta del consulado, en la que se encontró que de 106 personas, 99 establecían contacto varias veces por semana con familiares y amigos al sur de la frontera. Esto nos lleva a pensar en cómo las experiencias personales están ligadas a interacciones y experiencias mediadas de manera electrónica. Como señala Giddens (1991) con "el desarrollo de la 
comunicación de masas ... se enfatiza la interpenetración de la existencia propia con diversos sistemas sociales, incluso a escala global" (p. 29). Hecho el punto anterior, puede afirmarse que todos tenemos experiencias globales, dada la capacidad de "involucramiento local ... e interacción a distancia vía el uso de herramientas de compresión espacio-temporal" (Harvey, 1989, p. 147), que han provocado la "intensificación mundial de las relaciones sociales establecidas a lo largo de localidades distantes" (Giddens, 1990, p. 64). Una de las formas más ordinarias de vivir la globalización es a través de los medios de comunicación, que normalizan lo exótico, poniéndonos en contacto con lugares, pueblos y culturas que otrora resultaban ajenos. La transmisión de sucesos y eventos mediáticos tales como el deshielo de las capas polares, la Copa Mundial y la cobertura inmediata de desastres naturales y conflictos armados se suman para generar lo que John Tomlinson ha denominado como la "fenomenología de la conciencia global" (p. 30).

Para este caso se considera que las reflexiones de informantes mexicanos en Estados Unidos sobre las noticias de televisión permiten establecer su carácter como actores en un espacio transnacional. Esto se respalda en las consideraciones que los entrevistados hicieron a partir de las siguientes preguntas: ¿cuál es la última noticia por televisión que recuerda haber visto?, ¿por qué considera que esta noticia llamó su atención?, ¿cuál es la importancia de las noticias por televisión en su vida cotidiana? Se considera que las respuestas son válidas para reforzar el argumento en cuestión pues, aunque la recepción televisiva se relaciona con los contextos naturales donde se da la relación entre televidente y contenido, ésta también es parte de los "procesos de interpretación ... que anteceden y siguen al momento de ver" (Livingstone, 1998, p. 174). No es fortuito, además, que en una variedad de estudios de la recepción de noticias las personas se refieran a los reportes por televisión como si fueran "transparencias" de una realidad (Michelle, 2007, p: 195-198) que les incumbe en lo personal. Se propone, por lo tanto, que las noticias que los informantes consideraron de importancia ponen en relieve su condición como habitantes de un espacio transnacional. 


\section{REPORTES DE AQUÍ Y DE ALLÁ}

Uno de los aspectos fundamentales de la audiencia transnacional es el uso de las noticias para estar al tanto de los sucesos que tienen lugar en el país de origen (Karim, 2003; Robins \& Aksoy, 2001). El empleo de las noticias en este sentido fue hecho visible por una mujer radicada en Los Ángeles desde hace 26 años, quien recién había visto una noticia sobre "la ola de calor terrible que hay en Sonora. Estaba tan caliente que tenían que turnarse para entrar a un tambo de agua". Agregó que el reporte había capturado su atención "porque así es con todas las noticias de México ... las noticias son una forma de ir, de estar allá". Al ser cuestionada sobre la importancia que tenían las noticias televisivas en su vida cotidiana, la mujer expresó que éstas no eran algo que sólo "veo en la televisión", sino algo de lo que:

Se habla con la gente, si te encuentras con alguien en la calle, alguien de México, siempre hablas de las noticias, y claro, si hablas por teléfono le preguntas a tus parientes, "y qué tal con las protestas de López Obrador" y cosas así (Concepción, 64 años, Guadalajara).

Otro entrevistado habló sobre el reporte de una huelga de maestros en el estado de Oaxaca "que tiene más de 100 días en la que no ha habido una respuesta ni del gobierno ni de los maestros". Su interés en este proceso se debía a "que necesito estar al tanto de lo que pasa en mi país", y luego agregó que las noticias le funcionaban como una especie de monitor a través del cual podía evaluar la calma o los problemas de la realidad mexicana. Según él:

Estás aquí, trabajando para que tu gente allá viva un poco mejor, pero a veces miras las noticias, hablas con la gente, y ves que no cambia nada. Uno se pregunta, ¿para qué tanto trabajo? Todo el dinero que envías, y piensas que sería mejor concentrarte en traerte a tu familia y olvidar que algún día fuiste mexicano (Jesús, 48 años, Ciudad de México).

Las noticias por televisión pueden también poner en perspectiva elementos subjetivos de la vida en un espacio transnacional. Una madre 
relató, por ejemplo, cómo seguía impactada un día después de haber visto la cobertura de un tiroteo en el barrio angelino de Compton, en el que una niña de tres años había perdido la vida. El reporte, dijo, la hizo ponerse en la situación de la mamá de la niña y en las condiciones de inseguridad que imperan en Los Ángeles. Sin embargo, y un poco de manera sorpresiva, el informe la hizo pensar en su familia en México, luego que los parientes de la niña hicieron un llamado público por el fin de la violencia. La entrevistada razonó que:

Esta noticia me llamó sobre todo como madre, me hizo pensar en que soy madre aquí en Estados Unidos y en que también tengo una familia en México, y que a ambas las tengo que sacar adelante (Elba, 27 años, Jalisco).

Experimentar las noticias de televisión como una experiencia de ubicuidad puede darse de manera complementaria entre diferentes integrantes del hogar. Para una pareja, por ejemplo, las noticias ofrecen temas de discusión que fomentan la convivencia familiar, y que al mismo tiempo "te permiten pensar en las cosas que te interesan, en tus parientes en México, pero también lo de aquí en Estados Unidos, y lo del mundo que te puede afectar", dijo la parte masculina de un matrimonio. La mujer agregó que "a veces él sigue lo que está pasando en México y yo algo distinto, es casi como si nos pusiéramos de acuerdo para no ver la misma (noticia) y tener de qué hablar". En referencia a los reportes que habían visto esa mañana la pareja relató:

Vi lo de México, de la inundación en Reynosa, está sorprendente esa inundación, la gente estaba recuperando lo que podía de sus casas. Te pones a pensar en tu familia, aunque no vivan en ese lugar (Mario, 36 años, Mazatlán).

Lo que yo vi fue lo del Papa. Que por lo que él dijo ahora tiene una controversia con los musulmanes. No sé si lo dijo, yo no vi cuando dio su discurso, no sé si realmente se expresó bien o si sólo lo malinterpretaron (Inés, 40 años, Ciudad de México).

Pienso que el Papa usó unas frases que no debió usar, porque luego uno sabe que la religión es una de las principales causas de guerra en el mundo musul- 
mán, y luego ya ves lo que pasa, con el terrorismo, hasta somos los latinos los que vamos al frente a pelear las guerras de Estados Unidos... como en Irak, donde hay un montón de latinos (Mario, 36 años, Mazatlán).

Independientemente de que la recepción de noticias puede disparar interpretaciones descabelladas - como ligar las declaraciones del Papa con la guerra en Irak- éstas resultan de interés porque tienden a reflejar las preocupaciones de la audiencia transnacional no sólo en relación al país de origen, sino también en relación al entorno cotidiano. El punto en cuestión se hace visible a través del relato de un hombre en relación a varios reportes que había visto el día en que fue entrevistado:

Esta mañana vi el reporte del tráfico porque siempre lo veo mientras desayuno. También me impresioné con la noticia de una balacera cerca de Compton, que mataron a una niñita, y luego vi una noticia sobre la obesidad de los niños y de una disputa que tienen los maestros con el mayor (alcalde) Villarraigosa (Francisco, 42, Zacatecas).

La atención de la audiencia transnacional en una variedad de eventos es además de interés porque pone en perspectiva las diferentes dimensiones que dan forma a su percepción de la cotidianidad como algo que ocurre en múltiples capas geográficas. Así lo hizo suponer un informante cuando recordó noticias recientemente vistas: "Ahorita está el conflicto que hay en Irak y el de México en el estado de Oaxaca, y en el Distrito Federal, la situación del cambio de poder de presidente". Explicó que estos reportes eran de importancia para él porque:

Tengo varios conocidos aquí en Los Ángeles que tienen hijos peleando en Irak. La segunda, la de Oaxaca, porque es de mi país, cuando hay problemas allá casi siempre significa que más personas se vienen para acá. Y por lo del cambio de los presidentes yo en lo personal voté por el PRD, y pues esperaba otro cambio, pero salió lo mismo, otro fraude (Alfredo, 52 años, Ciudad de México).

Hay que destacar que la cobertura de la intervención militar de Estados Unidos en Irak fue un tema recurrente no sólo en las entrevistas del 
consulado sino en las múltiples actividades que fueron parte del programa de investigación del que se desprende este artículo. Un seguimiento cotidiano de los acontecimientos en Oriente Medio, en este sentido, hace suponer que la audiencia transnacional debe investigarse más allá de los criterios del binomio país de nacimiento-país de destino, dando un seguimiento a las razones y motivaciones que operan detrás de los procesos de interpretación que son parte de la recepción televisiva. En otras palabras, conceptualizar a la audiencia transnacional plantea el reto de asumir la complejidad de sus redes familiares y demás asociaciones que la caracterizan. Esta perspectiva puede ser de utilidad para entender, por ejemplo, a un entrevistado quien dijo que normalmente "no pongo ninguna atención a lo que pasa en las noticias de México. ¿Qué sentido tiene? Si quiero noticias de casa nada más llamó a mis papás y ya puedo saber todo lo que me interesa". Detrás del aparente desinterés en los reportes informativos de México se asomó además un disgusto hacia ciertos valores de producción de los noticieros en español, "porque los presentadores son gritones". Agregó que:

Prefiero las noticias en inglés, no siempre entiendo todo pero con las imágenes te das una idea. Y la cobertura de la guerra de Irak es mucho más completa, ésta me interesa verdaderamente porque tengo parientes allá peleando, y tengo conocidos que también tienen a sus familiares, a hijos, allá (Héctor, 49 años, Zacatecas).

\section{CONCLUSIÓN}

Esta intervención ha articulado el discurso del transnacionalismo con el análisis de la recepción como una forma de replantear el estudio de las audiencias formadas por públicos inmigrantes en los países desarrollados. Esta fusión da lugar a la "audiencia transnacional", un término que asume a los inmigrantes como actores sociales que participan en sus países de origen y destino. El concepto desecha el nacionalismo metodológico de perspectivas académicas que enmarcan la relación de la audiencia étnica o minoritaria en procesos de asimilación o mantenimiento cultural. Aunque en tiempos recientes sus argumentos han sido matizados, este paradigma es afín al modelo de transmisión hipodér- 
mica, y oscurece el hecho de que las experiencias de migración están imbricadas con los múltiples flujos humanos, materiales y simbólicos del proceso contemporáneo de globalización. Desde el punto de vista del análisis de la recepción, por el contrario, se tiene la posibilidad de visualizar a las comunidades transnacionales como consumidores y usuarios de los medios de comunicación, y como participantes en transacciones sociales y económicas que fluyen entre sus espacios privados y públicos. En el contexto de articulación estructural que es parte de regiones como la del TLCAN, estas transacciones modifican sin embargo nuestro entendimiento de lo privado y lo público, espacios que se distribuyen en diversas capas geográficas y que ponen en manifiesto las interacciones de la audiencia entre lo local y lo global. Lo importante aquí es aprender a valorar la medida en que esas interacciones, ya sean verbales o físicas, son informadas en menor o mayor medida por las noticias de televisión o por otras mediaciones. Esta idea puede vincularse al razonamiento de Jesús, el inmigrante nacido en la Ciudad de México, para quien las noticias de un conflicto en Oaxaca le hacían cuestionar su propio envío de remesas. También las palabras de Concepción son relevantes aquí, pues dejó claro que sus interacciones con otros mexicanos en Los Ángeles y con sus familiares en México a través del teléfono están por lo general salpicadas de la información que obtiene a través de los noticieros. Reflexiones como la de Elba, cuyas responsabilidades familiares al sur y al norte de la frontera salieron a flote después de ver un reporte sobre la muerte de una niña en Los Ángeles, sugieren que el análisis de la recepción puede servir para visualizar las experiencias de las comunidades transnacionales.

Es por supuesto necesario involucrarse en actividades de investigación que permitan crear esquemas de observación sistemáticos que den más claridad al carácter de las interacciones de la audiencia transnacional. Estas metodologías pueden situarse, por ejemplo, en el hogar, donde puede estudiarse el carácter de las relaciones familiares que ocurren en el contexto de la recepción de noticias televisivas. Se sabe que el carácter de las relaciones entre hombres y mujeres de las familias transnacionales atraviesa una erosión de las jerarquías de género basadas en estructuras patriarcales (Castells, 2004, p. 287; Hirsch, 2003). Esta tendencia interesa al análisis de recepción, al poner en duda la noción, por 
ejemplo, de que los hombres ven noticias y las mujeres novelas. Una experiencia reciente de investigación sugiere que, por el contrario, en la familia transnacional las mujeres ven más noticias que los hombres y que a menudo están mejor preparadas para interpretar su importancia para el entorno familiar (Moreno, 2009, pp. 170-177, 2010). De la misma manera, la audiencia transnacional puede ser una rica veta de trabajo para investigar el potencial de la relación entre consumo de información noticiosa y momentos de acción política (Jensen, 1998, p. 15). Las protestas de inmigrantes en Estados Unidos en 2006 contra la criminalización de residentes sin documentos, por ejemplo, estuvo estrechamente ligada a la información difundida por los noticieros en español (Flaccus, 2006). Paradójicamente, los mismos noticieros fueron irrelevantes para estimular el voto transnacional de los mexicanos en Estados Unidos durante la campaña presidencial de México en el mismo año. Hay elementos de sentido común que permiten generar explicaciones, pero los teóricos de la comunicación deben estar interesados en explorar la cuestión de manera científicamente sustentada. Este artículo, más que aspirar a aportar conclusiones contundentes, es un intento de ver el consumo mediático de los inmigrantes en un marco conceptual que pone en entredicho los paradigmas hasta ahora empleados para ese fin, pero el objetivo de conceptualizar a la audiencia transnacional es una obra en progreso.

\section{Bibliografia}

ACS-American Community Survey (2005-2007). US Census Bureau. Recuperado de http://factfinder.census.gov/servlet/DatasetMainPageServlet?_program $=$ ACS\&_submenuId $=$ datasets_2\&_lang $=$ en Ahmed, S. (1999). Home and away: narratives of migration and estrangement. International Journal of Cultural Studies, 2, 329-347. Ahmed, S. (2003). Uprootings/regroundings: questions of home and migration. Oxford: Berg.

Alasuutari, P. (Ed.). (1999). Rethinking the media audience. Londres: Sage.

Álvarez, R. (1994). Changing ideology in a transnational market: chile and chileros in Mexico and the US. Human Organization, 53, 255-262. Anderson, B. (1991). Imagined communities: reflections on the origin and spread of nationalism. Londres: Verso. 
Ang, I. (1991). Desperately seeking the audience. Londres: Routledge. Appadurai, A. (1996). Modernity at large: cultural dimensions of globalization. Minneapolis, Londres: University of Minnesota Press.

Appadurai, A. (2001). Grassroots globalization and the research imagination. En A. Appadurai (Ed.), Globalization. Duke University Press.

Arendt, H. (1998 [1958]). The human condition. Chicago, Londres: University of Chicago Press.

Basch, L. G., Schiller, N. G. \& Szanton, C. (1994). Nations unbound: transnational projects, postcolonial predicaments, and deterritorialized nation-states. Basel, Inglaterra: Gordon and Breach.

Bhabha, H. K. (1994). The location of culture. Londres: Routledge.

Bird, E. (2009). Not dead yet? Some thoughts on the future of qualitative audience studies. Transforming Audiences, 2. Londres.

Bogardus, E. S. (1923). Essentials of americanization. Los Ángeles: J.R. Miller.

Brah, A. (1996). Cartographies of diaspora: contesting identities. Londres: Routledge.

Brunsdon, C. (1981). "Crossroads": Notes on Soap Opera. Screen, 22, 32-37.

Bryce, J. (1987). Family time and TV use. En Thomas, L. (Ed.), Natural audiences. Norwood, NJ: Ablex.

Canovan, M. (1994). Politics as culture: Hannah Arendt and the public realm. En L. P. Hinchman (Ed.), Hannah Arendt: critical essays. Albany, Nueva York: Suny Press.

Castells, M. (2004). The power of identity. Malden: Blackwell.

Castles, S. \& Miller, M. J. (2003). The age of migration. Basingstoke, Palgrave: Macmillan.

Clifford, J. (1994). Diasporas. Cultural Anthropology, 9, 302-338.

Cohen, R. (1997). Global diasporas: an introduction. Seattle: University of Washington Press.

Constantakis, P. E. (1993). Spanish-language television and the 1988 presidential elections: a case study of the "dual identity" of ethnic minority media. Austin. Texas: The University of Texas at Austin.

Consulado (2009). Acerca del Consulado. Los Ángeles, Secretaría de Relaciones Exteriores. Recuperado el 30 de octubre de 2009 de http://www.sre.gob.mx/losangeles/ 
Corner, J. (1995). Television form and public address. Londres: Edward Arnold.

Cunningham, S. (2004) Popular media as public 'sphericules' for diasporic communities. En Allen, R. \& Hill, A. (Eds.) The Television Studies Reader. Londres: Routledge.

Dayan, D. \& Katz, E. (1992). Media events: the live broadcasting of history. Cambridge, MA; Londres: Harvard University Press.

Faist, T. (1999). Transnationalization in international migrations for the study of citizenship and culture. Working papers series, transnational communities programme. Oxford University. Recuperado el 25 de febrero de 2007 de http://www.transcomm.ox.ac.uk/working\%20 papers/faist.pdf.

Fiske, J. (1989). Understanding popular culture. Londres: Unwin Hyman.

Fiske, J. (1994). Media matters: everyday culture and political change. Minneapolis: University of Minnesota Press.

Flaccus, G. (2006). Spanish-language media play key role in promoting pro-immigrant rallies in U.S., Associated Press Newswires, Los Ángeles. Recuperado el 29 de marzo de 2006 de base de datos Factiva.com Foxnews.com (2007). Schwarzenegger to immigrants: avoid spanishlanguage media. San Francisco. Recuperado el 21 de mayo de 2008 de http://www.foxnews.com/printer_friendly_story/0,3566,282833,00. html

Fraser, N. (2007). Transnationalizing the public sphere: on the legitimacy and efficacy of public opinion in a postWestphalian world. En S. Benhabib, I. S. D. P. (Ed.), Identities, affiliations and allegiances. Cambridge: Cambridge University Press.

García-Canclini, N. (1995). Hybrid cultures: strategies for entering and leaving modernity. Minneapolis: University of Minnesota Press.

Gauntlett, D. \& Hill, A. (1999). TV living: television, culture, and everyday life. Nueva York: Routledge.

GCIM-Commission on International Migration (2005). Migration in an interconnected world: new directions for action. Recuperado el 26 de enero de 2099 de http://www.gcim.org/attachements/gcim-complete-report-2005.pdf

Georgiou, M. \& Silverstone, R. (2007). Diasporas and contra-flows be- 
yond nation-centrism. En Thussu, D. K. (Ed.), Media on the move: global flow and contra-flow. Londres: Routledge.

Giddens, A. (1984). The constitution of society: outline of the theory of structuration. Cambridge: Polity Press.

Giddens, A. (1990). The consequences of modernity. Stanford, CA: Stanford University Press.

Giddens, A. (1991). Modernity and self-identity: self and society in the late modern age. Cambridge: Polity Press Basil Blackwell.

Giddens, A. (1999). Runaway world: how globalisation is reshaping our lives. Londres: Profile.

Gillespie, M. (1995). Television, ethnicity and cultural change. Londres: Routledge.

Gillespie, M. (2002). Dynamics of diasporas: south asian media and transnational cultural politics. En G. Tufte (Ed.), Global Encounters: media and cultural transformation. Luton: University of Luton Press.

González, C. (1999). Fostering identities: Mexico's relations with its diaspora. The Journal of American History, 86, 545-567.

Gunter, B. \& Svennvig, M. (1987). Behind and in front of the screen: television's involvement with family life. Londres: Libbey.

Hall, S. (2001 [1980]). Encoding/Decoding. En Kellner, G. D. M. A. D. M. (Ed.), Media and cultural studies: keyworks. Malden, MA: Blackwell Publishers.

Handlin, O. (1973 [1951]). The uprooted: the epic story of the great migrations that made the american people. Boston: Little, Brown and Company.

Hannerz, U. (1996). Transnational connections: culture, people, places. Londres, Nueva York: Routledge.

Harvey, D. (1989). The condition of postmodernity: an enquiry into the origins of cultural change. Oxford: Basil Blackwell.

Held, D., Mcgrew, A., Goldblatt, D. \& Perraton, J. (1999). Global transformations: politics, economics and culture. Oxford: Polity.

Hill, A. (2007). Restyling factual TV: audiences and news, documentary and reality genres. Londres: Routledge.

Hirsch, S. (2003). A courtship after marriage: sexuality and love in Mexican transnational families. Los Angeles: University of California Press. 
Hobson, D. (1978). Housewives: isolation as oppression. En CCCS, W. S. S. G. (Ed.), Women take issue: aspects of women's subordination. Londres: Hutchinson.

Hobson, D. (1980). Housewives and the mass media. En S. Hall, D. H., Andrew \& P. Willis (Eds.), Culture, media, language: working papers in cultural studies 1972-79. Londres: Hutchinson.

Hobson, D. (1982). Crossroads: the drama of a soap opera. Londres: Methuen.

Huntington P., S. (2004). The hispanic challenge. Foreign Policy, 30-45.

Jenkins, H. (1992). Textual poachers: television fans \& participatory culture. Nueva York: Routledge.

Jenkins, H. (2006). Convergence culture: where old and new media collide. Nueva York, Londres: University Press.

Jensen, K. B. \& Rosengren, K. E. (1990) Five traditions in search of the audience. European Journal of Communication, 5, 207-238.

Jensen, K. B. (Ed.). (1998). News of the world: world cultures look at television news. Londres, Nueva York: Routledge.

Jensen-Leichter, H., Ahmed, D., Barrios, L., Bryce, J., Larsen, E. \& Moe, L. (1985). Family contexts of television. Educational Technology Research and Development, 33, 26-40.

Johnson, M. A. (2000). How ethnic are U.S. ethnic media: the case of latina magazines. Mass Communication and Society, 3, 229-248.

Karim, K. H. (2003). Mapping diasporic mediascapes. En Karim, K. H. (Ed.), The Media of Diaspora. Londres: Routledge.

Kolar-Panov, D. (1997). Video, war and the diasporic imagination. Londres: Routledge.

Leadbeater, C. (2008). We-think. Londres: Profile.

Lemish, D., Liebes, T. \& Seidmann, V. (2001). Gendered media meanings and uses. En Bovill, S. L. A. M. (Ed.), Children and their changing media environment: a european comparative study. Mawhaw, NJ: L. Erlbaum.

Levitt, P. (2001) Transnational migration: taking stock and future directions. Global Networks, 1, 195-216.

Liebes, T. \& Katz, E. (1990). The export of meaning: cross-cultural readings of Dallas. Nueva York, Oxford: Oxford University Press. 
Lindlof, T. R. (1987). Natural audiences. Nueva Jersey: Ablex.

Lindlof, T. R. (1988). Media audiences as interpretive communities. En J. Anderson (Ed.), Communication Yearbook 11. Newbury Park, CA: Sage.

Livingstone, S. M. (1998). Making sense of television: the psychology of audience interpretation. Nueva York: Routledge.

Long, N. \& Villarreal, M. (1998). Small product, big issues: value contestations and cultural identities in cross-border commodity networks. Development and Change, 29, 725-750.

Lull, J. (1980). The social uses of television. Human Communication Research, 6, 197-209.

Lull, J. (1982). How families select television programmes: a mass observational study. Journal of Broadcasting and Electronic Media, 24, 801-811.

Lull, J. (1990). Inside family viewing: ethnographic research on television's audience, Londres: Routledge.

Mandaville, P. (2002). Reading the state from elsewhere: towards an anthropology of the postnational. Review of International Studies, 28, 199-207.

Martín-Barbero, J. (1993). Communication, culture and hegemony: from the media to mediations. Londres: Sage.

Mayer, V. (2003). Producing dreams, consuming youth: mexican americans and mass media. New Brunswick: Rutgers University Press.

McAnany, E. \& Wilkinson, K. T. (1996). Mass media and free trade. Austin: University of Texas Press.

Michelle, C. (2007). Modes of reception: a consolidated analytical framework. The Communication Review, 10, 181-222.

Moores, S. (1993). Interpreting audiences: the ethnography of media consumption. Londres: Sage.

Moreno, G. (2009). Transnational audiences and the reception of television news: a study of mexicans in Los Angeles. Communication Media Research Institute. Londres: University of Westminster.

Moreno, G. (2010). Penar a la audiencia transnacional. Ponencia inextenso, presentada en el XXI Encuentro Nacional AMIC 2010, Ciudad de México, 2-4 de junio. 
Morley, D. (1980). The Nationwide audience: structure and decoding. Londres: British Film Institute.

Morley, D. (1986) Family television: cultural power and domestic leisure. Londres: Comedia.

Morley, D. \& Silverstone, R. (1992). Domestic communication-technologies and meanings. Media, Culture \& Society, 12, 31-55.

Morley, D. (2000). Home territories: media, mobility, and identity. Londres: Routledge.

Morley, D. (2006). Unanswered questions in audience research. The Communication Review, 9, 101-121.

Morley, D. \& Robins, K. (1995) Spaces of identity: global media, electronic landscapes and cultural boundaries. Londres, Nueva York: Routledge.

Naficy, H. (1993) The making of exile cultures: Iranian television in Los Angeles, Minneapolis, Londres: University of Minnesota Press.

Naficy, H. (2003) Narrowcasting in diaspora: Middle Eastern television in Los Angeles. En Karim, K. H. (Ed.), The Media of Diaspora. Londres: Routledge.

Negus, K. \& Román-Velázquez, P. (2000). Globalization and cultural identities. En Gurevitch, J. C. A. M. (Ed.), Mass media and society. Arnold.

Nevaer, L. (2007). For Mexico, "local residence" now includes New York and Los Angeles. Mexico City, New American Media.

Obama, B. (2009) Barack Obama's Inaugural Address. The New York Times. Recuperado el 12 de noviembre de http://www.nytimes. com/2009/01/20/us/politics/20text-obama.html?_r=1

Ong, A. (1999). Flexible citizenship: the cultural logics of transnationality. Durham: Duke University Press.

Orozco, G. (1998). Mexican mediations. En Jensen, K. B. (Ed.), News of the world. Nueva York, Londres: Routledge.

PEW (2006). The size and characteristics of the unauthorized migrant population in the U.S. Washington, D.C., Pew Hispanic Center. Recuperado el 7 de marzo de 2007 de http://pewhispanic.org/files/reports/61.pdf

Portes, A. (1997). Globalization from below: the rise of transnational communities. Working papers series, transnational communi- 
ties programme. Oxford University. Recuperado el 4 de febrero de 2009 de http://www.transcomm.ox.ac.uk/working\%20papers/ portes.pdf

Portes, A., Escobar, C. \& Arana, R. (2008). Bridging the gap: transnational and ethnic organizations in the political incorporation of immigrants in the United States. Ethnic and Racial Studies, 1-35.

Portes, A. \& Rumbaut, R. G. (2006). Immigrant America: a portrait. Berkeley, CA, Londres: University of California Press.

Ríos, D. I., Gaines Jr. \& Stanley, O. (1999). Latino media use for cultural maintenance. Journalism \& Mass Communication Quarterly, 75, 746-761.

Roberts, B. R., Frank, R. \& Lozano-Ascencio, F. (1999). Transnational migrant communities and Mexican migration to the US. Ethnic and Racial Studies, 22, 238-266.

Robertson, R. (1995). Glocalization: time-space and homogeneityheterogeneity. En M. Featherstone, S. L. A. R. R. (Ed.), Global modernities. Londres: Sage.

Robins, K. (1997). What in the world's going on? En P. D. Gay (Ed.), Production of culture/cultures of production. Sage.

Robins, K. \& Aksoy, A. (2001). From spaces of identity to mental spaces: lessons from Turkish-Cypriot cultural experience in Britain. Journal of Ethnic and Migration Studies, 27, 685-711.

Robins, K., \& Aksoy, A. (2005). Whoever looks always finds: transnational viewing and knowledge-experience. En J. K. Chalaby (Ed.), Transnational television worldwide: towards a new media order. Londres, Nueva York: I.B. Tauris.

Robins, K. \& Aksoy, A. (2006). Thinking through experiences: transnational media and migrants minds. En J. C. A. D. Morley (Ed.), Media and cultural theory. Londres: Routledge.

Rodríguez, A. (1999). Making latino news: race, language, class. Thousand Oaks, Londres, Nueva Delhi: Sage.

Rosaldo, R. (1993). Culture \& truth: the remaking of social analysis. Londres: Routledge.

Rouse, R. (1995). Questions of identity: personhood and collectivity in transnational migration to the United States. Critique of Anthropo$\log y, 15,351-380$. 
Rouse, R. (1996 [1991]). Mexican migration and the social space of postmodernism. En D. G. Gutiérrez, (Ed.), Between two worlds: mexican immigrants in the United States. Wilmington, Del.: Scholarly Resources.

Sabry, T. (2005). Emigration as popular culture. European Journal of Cultural Studies, 8, 5-22.

Sassen, S. (2001). The global city: New York, London, Tokyo. Princeton: Princeton University Press.

Schudson, M. (1995) The power of news. Cambridge: Harvard University Press.

Schudson, M. (2000). The sociology of news production revisited (again). En M. Gurevitch \& C. Curran (Eds.), Mass media and society. Londres: Arnold.

Silverstone, R. (1991). From audiences to consumers: the household and the consumption of communication and information technologies. European Journal of Communication, 6, 135-154.

Silverstone, R. (1994). Television and everyday life. Londres, Nueva York: Routledge.

Sinclair, J. (1996b). Mexico, Brazil, and the latin world. En J. Sinclair, E. J., S. Cunningham (Eds.), New patterns in global television: peripheral vision. Nueva York: Oxford University Press.

Sinclair, J. (1999). Latin American television: a global view. Oxford: University Press.

Sinclair, J. (2003). The Hollywood of Latin America: Miami as Regional Center in Television Trade. Television New Media, 3, 211-229.

Sinclair, J. (2004). From Latin Americans to Latinos: Spanish-language television in the United States and its audiences. Revista Fronteirasestudios midiaticos, VI, 7-20.

Sinclair, J. (2005). International television channels in the latin american audiovisual space. En J. K. Chalaby (Ed.), Transnational television worldwide: towards a new media order. Londres, Nueva York: I.B. Tauris.

Sklair, L. (1998). Transnational practices and the analysis of the global system. Working papers series, transnational communities programme. Londres: Oxford University-School of Economics and Political Science. Recuperado el 4 de febrero de 2009 de http://www. transcomm.ox.ac.uk/working\%20papers/sklair.pdf. 
Smith, A. D. (1999). Myths and memories of the nation. Oxford: University Press.

Smith, M. P. \& Guarnizo, L. E. (Eds.). (1998). Transnationalism from below. New Brunswick, Londres: Transaction Publishers.

Smith, M. P. \& Bakker, M. (2005). The transnational politics of the Tomato King: meaning and impact. Global Networks, 5, 129-146.

Smith, R. C. (1998). Transnational localities: community, technology and the politics of membership within the context of Mexico and U.S. migration. En M. Guarnizo, P. S. A. L. E. (Ed.), Transnationalism from Below. New Brunswick, Londres: Transaction Publishers.

Sreberny, A. (2000). Media and diasporic consciousness: an exploration among Iranians in London. En S. Cottle (Ed.), Ethnic minorities and the media: changing cultural boundaries. Buckingham, Philadelphia: Open University Press.

Subervi, F. (1986). The mass media and ethnic assimilation and pluralism: a review and research proposal with special focus on hispanics. Communication Research, 13, 71-96.

Subervi, F. \& Ríos, D. (2005). Latino identity \& situational latinidad. En E. D. Valle, (Ed.), Hispanic marketing and public relations: understanding and targeting america's largest minority. Boca Raton, FL: Poyeen Publishing.

Suro, R. \& Escobar, G. (2006). survey of mexicans living in the U.S. on absentee voting in mexican elections. Washington, D.C., Pew Hispanic Center. Recuperado el 29 de septiembre de 2009 de http:// pewhispanic.org/reports/report.php?ReportID $=60$

Telemundo (2008). Corporate information. Recuperado el 12 de marzo de 2008 de http://tv.telemundo.yahoo.com/corporativo/articulo/29092006/71/corporativo-corporate-information-english.html

Thompson, J. B. (1995). The media and modernity: a social theory of the media. Cambridge, Inglaterra: Polity Press.

Thussu, D. K. (2005). The transnationalization of television: the indian experience. En J. K. Chalaby (Ed.), Transnational television worldwide. Nueva York, Londres: I.B. Tauris.

Thussu, D. K. (2007). Media on the move: global flow and contra-flow. Londres, Nueva York: Routledge.

Tölölyan, K. (1991). The nation state and its others: in lieu of a preface. Diaspora, 1, 3-7. 
Tölölyan, K. (1996). Rethinking diaspora(s): stateless power in the transnational moment. Diaspora, 5, 3-36.

Tsagarousianou, R. (2001). A space where one feels at home: media consumption practices among London's South Asian and Greek Cypriot communities. En R. K. A. N. Wood (Ed.), Media and migration: constructions of mobility and difference. Londres, Nueva York: Routledge.

Univisión (2007). Annual report for the fiscal year ended December 31, 2007. New York, Securities and Exchange Commission filing, form 10-K. Recuperado el 12 de abril de 2008 de http://www.sec.gov/

Uribe, A. B. (2003). Re-imaginando México con la telenovela. Recepción cultural de telenovelas por inmigrantes mexicanos residentes en Los Ángeles, CA, Tijuana: El Colegio de la Frontera Norte.

Valdivia, A. N. (2003). Salsa as popular culture: ethnic audiences constructing an identity. En A. N. Valdivia (Ed.), A companion to media studies. Malden: Blackwell Publishing.

Vertovec, S. (1999). Conceiving and researching transnationalism. Ethnic and Racial Studies, 22, 447-462.

Williams, R. (2003 [1974]). Television: technology and cultural form. Londres: Routledge.

Wimmer, A. \& Glick-Schiller, N. (2002). Methodological nationalism and beyond: nation-state building, migration and the social sciences. Global Networks: A Journal of Transnational Affairs, 2, 301-334.

Yarto, C. \& Lozano, J. C. (2004). Televisión, rutinas y vida cotidiana en mujeres de México, Guadalajara y Monterrey [Television, routines and the everyday life of women in Mexico, Guadalajara y Monterrey]. Global media journal en español, Primavera 1-7. Recuperado el 2 de septiembre de 2005 de http://gmje.mty.itesm.mx/yarto_lozano.html 